\title{
Use of Blunt Scalp Hooks for Abdominal Procedure in Lumboperitoneal Shunt Placement: Technical Note
}

\author{
Takashi KAWAHARA, ${ }^{1}$ Takuichiro HIGASHI, ${ }^{1}$ Hiroshi TOKIMURA, ${ }^{2}$ \\ Kazunori ARITA, ${ }^{2}$ Masamichi ATSUCHI, ${ }^{1}$ and Koji TAKASAKI ${ }^{1}$ \\ ${ }^{1}$ Division of Neurosurgery, Atsuchi Neurosurgical Hospital, Kagoshima, Kagoshima; \\ ${ }^{2}$ Department of Neurosurgery, Kagoshima University Graduate School of Medical \\ and Dental Sciences, Kagoshima, Kagoshima
}

\begin{abstract}
In obese patients, we often find difficulty in laparotomy for placing a lumboperitoneal shunt catheter. The authors introduced an easy technique to get a sufficiently wide and shallow operative field through small abdominal incision in obese people. Four blunt scalp hooks and rubber bands, commonly used in craniotomy, were prepared. The fat layer and the rectus abdominis muscle layer were retracted and pulled up using these hooks. Blunt scalp hooks were useful for safe and effective retraction of abdominal wall, which made a sufficient and shallow operative field.
\end{abstract}

Key words: lumboperitoneal shunt, abdominal wall, blunt scalp hook, obesity

\section{Introduction}

Placement of lumboperitoneal shunt involves the procedure of abdominal region. ${ }^{1)}$ We had met some difficulties to perform a laparotomy especially in obese patients. ${ }^{2,3)}$ To overcome such problems, we introduced blunt hook with rubber ring (Fig. 1), routinely used for craniotomy, to retract the abdominal wall and to pull up peritoneal membrane.

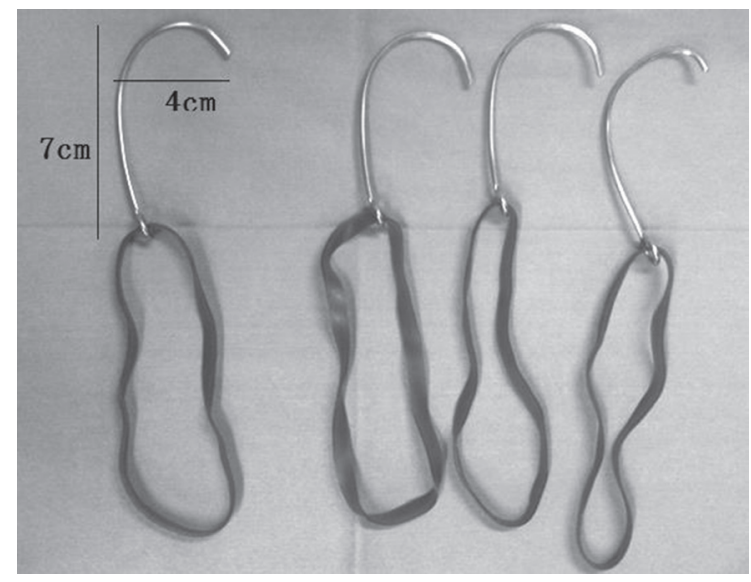

Fig. 1 Photograph showing four blunt scalp hooks with rubber ring.

Received December 19, 2013; Accepted January 14, 2014

\section{Surgical Technique}

Patient's abdominal region is covered with surgical drape. Small skin incision, $3-4 \mathrm{~cm}$ in length is made on the abdomen. Fat layer is opened with muscle retractors. After incision of anterior rectus sheath, the sheath is retracted with blunt scalp hooks with rubber ring fixed to surgical drape with Kocher forceps. After splitting rectus muscle, four blunt hooks are then put under the muscle layer, just on the posterior sheath. So, the operative field becomes widened and shallow (Fig. 2). Sufficient

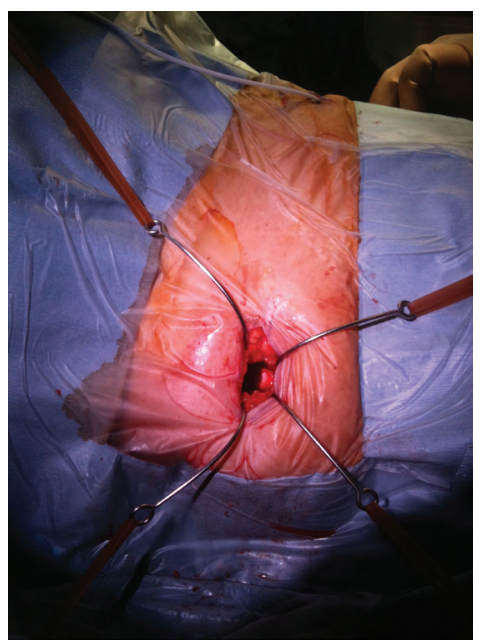

Fig. 2 Photograph showing four blunt scalp hooks with rubber ring retract operative field and elevate subcutaneous tissues. 
operative space is usually obtained with four hooks, two additional hooks are helpful in more obese patients.

\section{Results}

For the last 3 years, 125 consecutive patients underwent laparotomy using the hooks for lumboperitoneal shunting procedure. There were no difficulties and risks to reach peritoneum and to place abdominal catheter. The peritoneum was lifted up to an average of $2.8 \mathrm{~cm}$ in the recently operated five patients. Complications of lumboperitoneal shunt placement with this technique in 125 patients are summarized in Table 1. The frequency of abdominal catheter complications with our method is not high compared with previous report. ${ }^{3)}$

\section{Discussion}

Operative field in abdomen are often deep in obese patients. Using this method, we were able to get wide and shallow operative field. Scrubbed assistant for holding muscle retractor was not needed in the

Table 1 Complications of lumboperitoneal shunt placement in 125 patients

\begin{tabular}{llc}
\hline Location & Complication & No. of patients \\
\hline Lumber catheter & Migration & 1 \\
& Fracture & 4 \\
& Infection & 1 \\
Valve & Failure & 1 \\
Peritoneal catheter & & \\
& Migration & 4 \\
& Obstruction & 1 \\
\hline
\end{tabular}

procedure of shunt operation. Because the tip of blunt scalp hook is dull, we found no problems during the abdominal procedure with these hooks.

\section{Conclusion}

This simple method using blunt scalp hooks is safe, effective, and also economical for inserting abdominal catheter in lumboperitoneal shunt operation.

\section{Conflicts of Interest Disclosure}

None. All authors who are members of The Japan Neurosurgical society (JNS) have registered Online Self-reported COI Disclosure Statement Forms through the website for JNS members.

\section{References}

1) Selman WR, Spetzler RF, Wilson CB, Grollmus JW: Percutaneous lumboperitoneal shunt: review of 130 cases. Neurosurgery 6: 255-257, 1980

2) Nagasaka $T$, Inao $S$, Ikeda $H$, Tsugeno $M$, Okamoto $T$ : Subcutaneous migration of distal ventriculoperitoneal shunt catheter caused by abdominal fat pad shift-three case reports. Neurol Med Chir (Tokyo) 50: 80-82, 2010

3) Wang VY, Barbaro NM, Lawton MT, Pitts L, Kunwar S, Parsa AT, Gupta N, McDermott MW: Complications of lumboperitoneal shunts. Neurosurgery 60: 1045-1048; discussion 1049, 2007

Address reprint requests to: Hiroshi Tokimura, $\mathrm{MD}, \mathrm{PhD}$, Department of Neurosurgery, Graduate School of Medical and Dental Sciences, Kagoshima University, 8-35-1 Sakuragaoka, Kagoshima, Kagoshima 890-8544, Japan.

e-mail: tokimura@m3.kufm.kagoshima-u.ac.jp 